\title{
Agôn
}

Revue des arts de la scène

Critiques | Saison 2016-2017

\section{Les Parisiens, texte et mise en scène Olivier Py}

Paris est une défaite - Tristesse politique des Parisiens d'olivier Py

Julie Briand

\section{CpenEdition}

Journals

Édition électronique

URL : http://journals.openedition.org/agon/4025

DOI : 10.4000 /agon.4025

ISSN : 1961-8581

Éditeur

Association Agôn

Référence électronique

Julie Briand, "Les Parisiens, texte et mise en scène Olivier Py », Agôn [En ligne], Critiques, mis en ligne le 18 juillet 2017, consulté le 23 septembre 2020. URL : http://journals.openedition.org/agon/4025 ;

DOI : https://doi.org/10.4000/agon.4025

Ce document a été généré automatiquement le 23 septembre 2020

Association Agôn et les auteurs des articles 


\section{Les Parisiens, texte et mise en scène Olivier Py}

Paris est une défaite - Tristesse politique des Parisiens d'Olivier Py Julie Briand

\section{RÉFÉRENCE}

Les Parisiens, texte et mise en scène Olivier Py, du 8 au 15 juillet, La FabricA, Festival d'Avignon In.

1 La dernière représentation avignonnaise des Parisiens d'olivier Py a eu lieu le 15 juillet. Le temps éclair des critiques étant déjà plus ou moins écoulé, je renonce à ce périlleux exercice pour poser une question aux spectateurs : n'y a-t-il rien qui vous choque?

2 Je ne parle pas de toutes les outrances qui traversent le spectacle, de l'énorme godemichet rouge sang, des pipes et des doigts dans le cul, du vieil homme prêt à payer 500000 euros par an pour que son chien se fasse sodomiser par un homme. Les mœurs et les fantasmes des Parisiens, exhibés à grand renfort de nudités et de scènes sadomasochistes, n'ont aucune part dans mon malaise. Celui-ci tient à la représentation assumée, festive et sans alternative (sinon très marginale, nous y reviendrons) de l'effondrement du politique dans le domaine dit « culturel ».

3 Ainsi, en 2017, le directeur du Festival d'Avignon met en scène dans son fief, espace et symbole encore à peu près vaillant du théâtre public, la défaite du politique, l'arrivisme et le cynisme absolus des élites, la soif d'argent et de pouvoir dénuée d'un quelconque idéal - et tout cela (car jusqu'ici, rien que de très familier) est présenté comme une grande farce, un vaste carrousel où tout virevolte, rien n'est grave et où l'on rit de bon cœur en entendant que les directeurs de nos institutions culturelles, les élus de notre République et leurs conseillers, les mécènes soit disant férus d'art et de culture, bref, les subventionnés et les subventionneurs, ne forment qu'une "chaîne sans fin de lécheurs de cul». 
Cette phrase conclue le long monologue liminaire au cours duquel le célèbre chef d'orchestre Milo Venstein (Jean Alibert) dépeint le milieu culturel parisien comme un mouchoir de poche où les carrières se font et se défont, une vaste maison de passe où chacun vend son cul et son âme, où l'intégrité et la loyauté sont depuis bien longtemps rayées du dictionnaire. Un milieu de partouzeurs sous antidépresseurs, de requins sur le retour et de Rastignac aux dents de loups, de femmes collées au plafond de verre et d'hommes qui l'explosent. La fin de ce monologue - ô surprise venant d'un public avignonnais plutôt très discipliné - est copieusement applaudie par les spectateurs. Bien sûr, l'écriture est brillante, cruelle et drôle. Bien sûr, le comédien en fait une interprétation magistrale. Bien sûr, on s'est bien marré. Le directeur du Festival n'a pas ménagé sa verve, et il a habillé les Parisiens pour l'hiver.

Mais en fait, qu'est-il, lui ? Et que nous propose-t-il, sinon le tableau fasciné du milieu qui l'a propulsé et auquel il appartient encore? Parmi les innombrables intrigues érotico-amoureuses et politico-culturelles qui s'entremêlent, il y a celle de Touraine et Sarazac, anciens amants désormais au coude à coude sur la short-list de la direction de l'Opéra de Paris. L'un voit sa place de favori lui glisser entre les doigts au profit de l'autre, «très proche de la femme du président et du CAC 40 , capable de réunir des fortunes en mécénat ». Amère transposition de la non-reconduction d'Olivier Py à la tête du Théâtre de l'odéon en 2012, le ministre de la Culture d'alors, Frédéric Mitterrand, lui ayant préféré Luc Bondy. Le personnage de Touraine, qui semble ne plus avoir aucune chance tant les dés sont pipés, se voit conseiller de mettre le paquet sur la démocratisation culturelle : ateliers, rencontre avec les scolaires, projets participatifs... En réalité, il n'a rien à défendre, sinon sa propre ascension. En l'absence de mécènes et de juteux partenariats public/privé, il devra jouer son va-tout : la bonne vieille carte de la démocratisation culturelle.

6 Ce monde à la fois perverti et bien établi, nous vivons tous les jours dedans. Il faudrait être bien naïf pour s'écrier «Quelle horreur ! » en le voyant représenté sur scène. Mais y'a-t-il de quoi rire? Est-ce drôle, vraiment, un jeune homme de province qui se prostitue à un grand chef d'orchestre pour tenter de faire sa place dans le milieu culturel parisien? Et une vieille conseillère - seule personnage féminin de ce milieu-là - qui œuvre dans l'ombre à la réussite des hommes? Et un ministre de la culture qui n'est rien qu'un bouffon ravagé, humilié et torturé par ses problèmes d'ego ? A quel point faut-il avoir intégré ce système, ou à quel point faut-il s'en fiche, pour rire devant ce désastre?

7 Etrange bicéphalie d'Olivier Py, qui dans une même édition du Festival d'Avignon met en scène des Parisiens sans issue et un Hamlet militant et gratuit, interprété par des détenus du centre pénitentiaire du Pontet. L'engagement politique sincère n'est au demeurant pas totalement absent des Parisiens, mais il résiste à la micro-marge de la société, incarné par un groupe de prostituées activistes qui travaillent, entre autres, à la «Déclaration universelle des droits de la pute ». Dans un monde où l'idée même de transformation sociale semble avoir été sacrifiée sur l'autel de la concurrence généralisée, ces putes sont finalement celles qui se prostituent le moins. Leurs apparitions régulières sont des bouffées d'air pour le spectateur. Enfin on peut rire franchement, enfin on croit et l'on se bat pour quelque chose. «Je suis une vieille pute pas chère, et je suis au service au prolétariat!» s'exclame la merveilleuse Gilda (Moustafa Benaïbout). S'exclamant ainsi, elle arrache à la représentation un petit bout d'humanité. 
8 Mais Gilda et ses camarades ne peuvent pas sauver à elles seules $4 \mathrm{~h} 30$ de spectacle. Face à la scénographie mobile imaginée par Pierre-André Weitz - sol à damier et grandes façades haussmanniennes - on pense à la phrase de Tancredi dans Le Guépard: " Si nous voulons que tout reste tel que c'est, il faut que tout change ${ }^{1} »$. Alors, oui, faisons tourner les décors sur eux-mêmes, faisons courir et hurler les acteurs (dont la performance physique est indéniable), disons sans mâcher nos mots l'indigence et le cynisme de nos élites, et, lorsque tout cela sera fini, allons boire du champagne avec madame la Ministre, entre « gens qui réussissent ». A la vôtre/vautre.

\section{NOTES}

1. Le Guépard, Giuseppe Tomasi di Lampedusa, traduit de l'italien par Jean-Paul Manganaro, Paris, Points, 2007. 